\title{
Preparation and hydrogen storage capacity of highly porous activated carbon materials derived from polythiophene
}

\author{
M. Sevilla $a^{\mathrm{a}, \mathrm{b}}$, A.B. Fuertes ${ }^{\mathrm{a}}$ and R. Mokaya ${ }^{\mathrm{c}}$ \\ ${ }^{a}$ Instituto Nacional del Carbón (CSIC), P.O. Box 73, 33080 Oviedo, Spain \\ ${ }^{\mathrm{b}}$ Max Planck Institute of Colloids and Interfaces, Am Mühlenberg 1, 14424 Potsdam, \\ Germany \\ c School of Chemistry, University of Nottingham, University Park, Nottingham NG7 \\ 2RD, U. K. \\ * Corresponding author. Tel.: +49-331-567 9563; fax: +49-331-567 9502. E-mail \\ address: marta.sevilla@mpikg.mpg.de; martasev@incar.csic.es
}

\begin{abstract}
Highly porous carbons have been successfully synthesized by chemical activation of polythiophene with $\mathrm{KOH}$. The activation process was performed under relatively mild activation conditions, i. e., a $\mathrm{KOH} /$ polymer weight ratio of 2 and reaction temperatures in the $600-850{ }^{\circ} \mathrm{C}$ range. The porous carbons thus obtained possess very large surface areas, up to $3000 \mathrm{~m}^{2} / \mathrm{g}$, and pore volumes of up to $1.75 \mathrm{~cm}^{3} / \mathrm{g}$. The pore size distribution of these carbons can be tuned via modification of the activation temperature. Thus, by increasing the activation temperature from 600 to $850{ }^{\circ} \mathrm{C}$, the nature of the carbons changes gradually from microporous to micro-mesoporous (with small mesopores of up to $2.5 \mathrm{~nm}$ ). The polythiophene-derived activated carbons are sulfur-doped with sulfur contents in the $3-12 \mathrm{wt} \%$ range. The sulfur content decreases at higher activation temperature. The hydrogen storage capacity of these activated carbons, at cryogenic temperature and $20 \mathrm{bar}$, is up to $5.71 \mathrm{wt} \%$ with an estimated maximum hydrogen uptake of $6.64 \mathrm{wt} \%$. Their ease of preparation and high uptake makes the polythiophene-derived carbons attractive hydrogen storage materials.
\end{abstract}

Keywords: porosity; sulfur doping; hydrogen storage; polythiophene 


\section{Introduction}

The fabrication of porous carbons with optimized and tailored structural and chemical properties is key to their use in numerous emergent applications such as storage of electrical energy in supercapacitors [1], immobilization and separation of large biomolecules [2], $\mathrm{CO}_{2}$ capture [3], methane [4] or hydrogen storage [5], adsorption of specific contaminants in liquid phase (e. g., dyes, heavy metal ions, anions, etc) [6], catalyst supports in fuel cells [7], etc. Whereas for the immobilization and separation of large biomolecules and catalyst supports in fuel cells, mesoporous materials are regarded as the best candidates $[2,7]$, for energy storage or gas sorption applications, microporous materials exhibit the best performance [1, 3-5, 8]. Gas and energy storage are currently attracting much attention due to the ever-increasing demand for energy and the environmental problems caused by society's continuing dependence on fossil fuels. Therefore, much research effort is currently directed towards the design of materials that are tailored for use in energy-related gas and energy storage applications. In particular, the development of materials for efficient hydrogen storage remains a challenge. Porous materials are able to store hydrogen by physisorption and several studies have shown that narrow micropores, of size $0.6-0.7 \mathrm{~nm}$, are the most efficient for hydrogen storage [ 9 , 10]. However, large surface area and high pore volume are also necessary to ensure high hydrogen uptake and can sometimes compensate for the presence of less efficient larger $(>1.0 \mathrm{~nm})$ pores $[9,11,12]$

A possible synthesis strategy to suitable hydrogen stores is the production of carbon materials with ultra high surface area and pore volume. It is often the case that the nature of carbon precursors plays an important role in determining the textural properties of 
carbon materials generated via templating or activation processes $[3-6,11,13-16]$. The carbon precursors can also enable the doping of heteroatoms onto templated or activated carbons $[11,14]$. Here we present for the first time the one-step chemical activation (with $\mathrm{KOH}$ as activating agent) of the polymer polythiophene, as a way to achieving carbon materials with high surface area and large pore volume. The textural properties and chemical composition of the resulting S-doped porous carbons were tuned by modifying the activation temperature while retaining a relatively low $\mathrm{KOH} /$ polythiophene weight ratio of 2 . In this way, a variety of highly porous carbons with varying $\mathrm{S}$ content were obtained. We present and demonstrate the effectiveness of the polythiophene-derived activated carbons as attractive hydrogen stores.

\section{Materials and methods}

\subsection{Synthesis of porous carbons}

Polythiophene (PTh) was prepared using $\mathrm{FeCl}_{3}$ as oxidant. In a typical synthesis, $3 \mathrm{~g}$ of 2-thiophenemethanol (Aldrich) in $20 \mathrm{~mL}$ of acetonitrile, $\mathrm{CH}_{3} \mathrm{CN}$, (Aldrich) were slowly added, under vigorous stirring, to a solution of $\mathrm{FeCl}_{3}(28.9 \mathrm{~g}$, Aldrich) in $100 \mathrm{~mL}$ acetonitrile. The resulting mixture was stirred for $15 \mathrm{~h}$ at room temperature. The obtained polymer (PTh) was separated by filtration, washed with distilled water and then with acetone. Finally, it was dried at $120^{\circ} \mathrm{C}$. The PTh yield was around $95 \%$. The complete removal of iron compounds arising from the oxidant, $\mathrm{FeCl}_{3}$, was confirmed by thermogravimetric analysis; no inorganic residue remained after combustion of the carbonaceous matter. 
Polythiophene was chemically activated as follows; a mixture of PTh and $\mathrm{KOH}$ $(\mathrm{KOH} / \mathrm{PTh}$ weight ratio $=2)$ was heated under nitrogen up to a target temperature in the range $600-850{ }^{\circ} \mathrm{C}$ (heating rate: $3{ }^{\circ} \mathrm{C} / \mathrm{min}$, holding time: $1 \mathrm{~h}$ ). The activated samples were then thoroughly washed several times with $\mathrm{HCl}(10 \mathrm{wt} \%)$ to remove any inorganic salts and then washed with distilled water until neutral $\mathrm{pH}$. Finally, the carbons were dried in an oven at $120^{\circ} \mathrm{C}$. The activated carbons thus synthesized were denoted as ACT$x$, where $x$ is the activation temperature (in ${ }^{\circ} \mathrm{C}$ ).

\subsection{Characterization}

The textural properties of the carbons were determined by nitrogen sorption analysis at $-196{ }^{\circ} \mathrm{C}$ using a conventional volumetric sorptometer (Micromeritics ASAP 2020). The surface area was calculated by the BET method based on adsorption data in the relative pressure $(\mathrm{P} / \mathrm{Po})$ range of 0.04 to 0.2 and the total pore volume was determined from the amount of nitrogen adsorbed at a relative pressure of 0.99 . The micropore surface area and micropore volume were obtained via t-plot analysis. Pore size distribution (PSD) was determined via a Non Local Density Functional Theory (NLDFT) method using nitrogen adsorption data and assuming a slit pore model. Scanning electron microscopy (SEM) images were obtained using a Quanta FEG650 (FEI) instrument. Transmission electron micrographs (TEM) were taken on a JEOL (JEM-2000 EX II) microscope operating at $160 \mathrm{kV}$. A LECO Tru Spec microanalyzer was used to calculate the chemical composition $(\mathrm{C}, \mathrm{H}, \mathrm{O})$ of the materials. The sulphur content of the samples was determined by a LECO S-632 analyzer.

Hydrogen uptake measurements. The hydrogen uptake capacity of the carbons was measured by gravimetric analysis with an Intelligent Gravimetric Analyser, IGA, (Hiden) 
using $99.9999 \%$ purity hydrogen additionally purified by a molecular sieve filter. The hydrogen uptake measurements were performed at $-196{ }^{\circ} \mathrm{C}$ (in a liquid nitrogen bath) over the pressure range 0 to 20 bar. The uptake data were corrected for the buoyancy of the system and samples. The hydrogen uptake was calculated on the basis of a density of $1.5 \mathrm{~g} / \mathrm{cm}^{3}$ (helium density) for the carbons.

\section{Results and discussion}

Figure 1 illustrates the synthesis process of the activated carbons from polythiophene. Firstly, 2-thiophenemethanol is polymerized with the aid of $\mathrm{FeCl}_{3}$, giving rise to the polymer shown in the SEM image in Figure 1a. The polythiophene polymer is composed of microspheres of diameter $0.3-1.3 \mu \mathrm{m}$. On chemical activation with $\mathrm{KOH}$, the polythiophene is converted to an activated carbon with completely different particle morphology. Thus, the activated carbons exhibit a sponge-like structure consisting of highly vesiculated irregular shaped particles of relatively large size $(>40 \mu \mathrm{m})$, as shown in Figure 1b. As can be seen in Figure 1c, the porosity of the activated carbons arises from randomly distributed but uniformly sized micropores. The porosity of the activated carbons was probed by nitrogen sorption analysis. The nitrogen sorption isotherms in Figure 2a clearly show a microporous nature for carbons activated at $600{ }^{\circ} \mathrm{C}$ (ACT-600) and $700{ }^{\circ} \mathrm{C}$ (ACT-700). On the other hand, the isotherms of carbons activated at $750{ }^{\circ} \mathrm{C}$ and above indicate a mainly microporous nature but with some mesoporosity. However, it is noted that all the isotherms exhibit high nitrogen uptake at relative pressures lower than 0.02 due to micropores, and additionally, for temperatures $\geq 750{ }^{\circ} \mathrm{C}$, small mesopores are also evident, as indicated by the slope in the relevant isotherms at relative 
pressure $(\mathrm{P} / \mathrm{Po})$ in the range $0.1-0.3$. The plateau in the nitrogen isotherms is reached at increasingly higher relative pressures (in the range 0.15 to $\sim 0.5$ ) for carbons activated at higher temperature, which suggests an enlargement of pore size. This is corroborated by the pore size distribution (PSD) curves in Figure 2b. The PSD curves indicate that all the activated carbons are bimodal. However, whereas for ACT-600 and ACT-700 both pore size maxima lie below $2 \mathrm{~nm}$ (i.e., 0.9 and $1.3 \mathrm{~nm}$ for ACT-600 and 0.9 and 1.9 for ACT700), for the samples activated at $750^{\circ} \mathrm{C}$ and above, the larger pore size maxima is at 2.0 $-2.5 \mathrm{~nm}$ (the smaller being $1.2 \mathrm{~nm}$ for all three samples). A clear increase in pore size is thus registered at higher activation temperatures.

The textural parameters of the samples, determined from adsorption data, are summarized in Table 1. It can be seen that all the samples exhibit large surface area, in the range $1800-3000 \mathrm{~m}^{2} / \mathrm{g}$, with more than $77 \%$ arising from micropores. As expected from the enlargement of pore size at higher activation temperature, the contribution of micropores to the total surface area decreases with the activation temperature. The pore volumes are also high, between $\sim 0.9$ and $1.8 \mathrm{~cm}^{3} / \mathrm{g}$. These textural parameters are superior to those achieved by simple carbonization of the polythiophene polymer at 800 ${ }^{\circ} \mathrm{C}$ (i.e., surface area of $550 \mathrm{~m}^{2} / \mathrm{g}$ and pore volume of $0.43 \mathrm{~cm}^{3} / \mathrm{g}$ ). Overall, the textural data indicate that highly microporous materials $\left(\mathrm{S}_{\text {microp }}>1700 \mathrm{~m}^{2} / \mathrm{g}\right)$ can be achieved via simple chemical activation (with $\mathrm{KOH}$ ) of polythiophene. Of particular note is the fact that these highly porous carbon materials are prepared using a low (i.e. 2) ratio of $\mathrm{KOH}$ to the carbon (polythiophene).

The chemical composition of the polythiophene polymer and the activated carbons is presented in Table 1 . The polythiophene polymer contains $\sim 28 \mathrm{wt} \%$ sulfur, a content that 
is significantly lower than that of the unsubstituted polythiophene $(\sim 38 \mathrm{wt} \%)$. The apparent lower sulfur content in the polymer is due to the presence of $\sim 11 \mathrm{wt} \%$ oxygen, which arises from the oxidative polymerization process. When polythiophene is carbonized at $800{ }^{\circ} \mathrm{C}$, half of the sulfur is removed, while activation of the polymer causes a decrease in sulfur content of between 70 and $91 \%$ with greater loss at higher activation temperature. This suggests the preferential removal of sulfur (compared to carbon) during the activation process. Nevertheless, the sample activated at the lowest temperature, ACT-600, contains a large amount of sulfur $(11.8 \mathrm{wt} \%)$. This is one of the largest sulfur contents ever reported for a highly activated carbon. We have previously observed [13] that the sulphur present in these polythiophene-derived activated carbons exists in the form of sulphide (-C-S-C-) and sulphone (-C-S $\left.(\mathrm{O})_{2}-\mathrm{C}-\right)$ bridges which connect the aromatic rings, as schematically illustrated in Figure 1.

The hydrogen storage capacity of the high surface area S-doped carbon materials was determined at liquid nitrogen temperature $\left(-196^{\circ} \mathrm{C}\right)$ via a gravimetric method at pressures of up to 20 bar. Figure 3 a shows the total hydrogen uptake isotherms for the various activated carbons. The hydrogen uptake isotherms are completely reversible and exhibit no saturation in the $0-20$ bar pressure range, which suggests that higher hydrogen uptakes can be obtained if the pressure is increased beyond 20 bar. In this sense, the Langmuir model was used to estimate the maximum hydrogen storage capacity from the experimental data [14]. The values of the estimated maximum hydrogen uptake along with the experimental uptake at 1 and 20 bar are shown in Table 1 . The hydrogen storage capacity is in the range $4.6-5.7 \mathrm{wt} \%$. As illustrated in Figure $3 \mathrm{~b}$, the hydrogen uptake of the present carbons is generally superior to that of other comparable activated carbons 
with the same or higher surface area (open triangles in Figure 3b) [15-17], and is comparable or superior to that of metal organic frameworks (MOFs) of similar surface area (open diamonds in Figure 3) [18-20]. Furthermore, the hydrogen uptake is in line with that of activated carbons previously prepared by our group from hydrothermally carbonized materials (open circles in Figure 3b) [21]. We note that comparisons of the performance of the present carbons as hydrogen stores with other types of materials such as MOFs should always take into account the relative simplicity and attractiveness of activated carbon synthesis. The estimated maximum hydrogen uptake (obtained using Langmuir plots [14]) is in the range $5.3-6.6 \mathrm{wt} \%$.

It is noteworthy that, in Figure 3b, the carbons with smaller pores (i.e., ACT-600 and ACT-700) are above the Chahine rule line (slope $=1.0 \times 10^{-2} \mathrm{mmol} \mathrm{H}_{2} / \mathrm{m}^{2}$ ) [22], represented by the solid line in Figure $3 b$, whereas those with larger pores (i.e., at least one pore size system in the mesopore range) fall just below. Regarding the likely influence of S-doping on hydrogen storage, if we compare the hydrogen uptake density $\left(\mu \mathrm{mol} \mathrm{H}_{2} / \mathrm{m}^{2}\right)$ of the materials with the highest S content, i.e. ACT-600 and ACT-700, with that of other $\mathrm{KOH}$-activated carbons (which in principle will possess similar oxygen content) with similar PSD prepared by us [21] and Fierro et al. [17], it can be seen that it is similar $\left(\sim 12 \mu \mathrm{mol} \mathrm{H}_{2} / \mathrm{m}^{2}\right)$. From this comparison, it seems that $\mathrm{S}$ does not have influence on the hydrogen storage capacity of carbon materials under cryogenic conditions. As previously reported by many authors, a decrease in the hydrogen uptake density takes place as pore size increases and the proportion of microporosity reduces (see Table 1). However, the highest hydrogen uptake is achieved by the carbon sample with the highest surface area and pore volume, even though it possesses pores that are 
less efficient for hydrogen uptake. It is likely that the sheer magnitude of the surface area and pore volume compensate for the lower uptake efficiency of the mesopores.

\section{Conclusions}

In summary, highly porous carbons with tunable pore size distribution in the micropore to small mesopore range, surface area and pore volume of up to $3000 \mathrm{~m}^{2} / \mathrm{g}$ and $1.75 \mathrm{~cm}^{3} / \mathrm{g}$ respectively, and notable hydrogen storage capacity, have been synthesized for the first time from the polymer polythiophene. This has been achieved through chemical activation of the polymer with $\mathrm{KOH}$ at a low $\mathrm{KOH} /$ polythiophene ratio of 2 . The tuning of pore size was performed by modifying the activation temperature in the range $600-$ $850{ }^{\circ} \mathrm{C}$. Thus, for example, whereas the carbon activated at $600{ }^{\circ} \mathrm{C}$ mainly contains micropores of size $\sim 1 \mathrm{~nm}$, that obtained at $850^{\circ} \mathrm{C}$ exhibits two pore systems at $\sim 1 \mathrm{~nm}$ and $\sim 2.5 \mathrm{~nm}$. Additionally, these porous carbons have large sulfur content in the range $3-12$ wt $\%$, with higher content for low activation temperature samples. The hydrogen storage capacity of the carbons at cryogenic temperature and 20 bar is up to $5.71 \mathrm{wt} \%$, an uptake achieved for the sample with the largest pore volume (i.e. that activated at $850{ }^{\circ} \mathrm{C}$ ) and which is superior to the hydrogen uptake of other types of activated carbons that have similar or higher surface area.

\section{Acknowledgments}

The financial support provided by the Spanish MCyT (MAT2008-00407) is gratefully acknowledged. M. S. thanks the Spanish MCyT for the award of a Postdoctoral Mobility contract. 


\section{References}

[1] Su DS, Schlögl R. Nanostructured Carbon and Carbon Nanocomposites for Electrochemical Energy Storage Applications. ChemSusChem 2010; 3: 136-8.

[2] Vinu A, Miyahara M, Ariga K. Biomaterial Immobilization in Nanoporous Carbon Molecular Sieves: Influence of Solution pH, Pore Volume, and Pore Diameter. J Phys Chem B 2005; 109: 6436-41.

[3] Choi S, Drese JH, Jones CW. Adsorbent Materials for Carbon Dioxide Capture from Large Anthropogenic Point Sources. ChemSusChem 2009; 2: 796 - 854.

[4] Yeon SH, Osswald S, Gogotsi Y, Singer JP, Simmons JM, Fischer JE, Lillo-Rodenas MA, Linares-Solano A. Enhanced methane storage of chemically and physically activated carbide-derived carbon. J Power Sources 2009; 191: 560-7.

[5] Yürüm Y, Taralpa A, Veziroglu TN. Storage of hydrogen in nanostructured carbon materials. Int J Hydrogen Energ 2009; 34: 3784-98.

[6] $\mathrm{Wu} \mathrm{Z}$, Zhao DY. Ordered mesoporous materials as adsorbents. Chem Comm 2011; 47: $3332-8$.

[7] Chan K-Y, Ding J, Ren J, Cheng S, Tsang KY. Supported mixed metal nanoparticles as electrocatalysts in low temperature fuel cells. J Mater Chem 2004; 14: 505-16.

[8] Chmiola J, Yushin G, Gogotsi Y, Portet C, Simon P, Taberna PL. Anomalous Increase in Carbon Capacitance at Pore Sizes Less Than 1 Nanometer. Science 2006; 313: 1760-3.

[9] Gogotsi Y, Portet C, Osswald S, Simmons JM, Yildirim T, Laudisio G, Fischer JE. Importance of Pore Size in High Pressure Hydrogen Storage by Porous Carbons. Int J Hydrogen Energy 2009; 34: 6314-9. 
[10] Bhatia SK, Myers AL. Optimum conditions for adsorptive storage. Langmuir 2006; 22: $1688-700$

[11] Sevilla M, Mokaya R, Fuertes AB. Ultrahigh surface area polypyrrole-based carbons with superior performance for hydrogen storage, Energ. Environ. Sci, Accepted.

[12] Zhao W, Fierro V, Zlotea C, Aylon E, Izquierdo MT, Latroche M, Celzard A. Activated carbons with appropriate micropore size distribution for hydrogen adsorption. Int J Hydrogen Energ 2011; 36: 5431-4.

[13] Sevilla M, Fuertes AB. Highly porous S-doped carbons. Carbon, Submitted.

[14] Yang Z, Xia Y, Mokaya R. Enhanced hydrogen storage capacity of high surface area zeolite-like carbon materials. J Am Chem Soc 2007; 129: 1673-9.

[15] Jordá-Beneyto M, Suárez-García F, Lozano-Castelló D, Cazorla-Amorós D, LinaresSolano A. Hydrogen storage on chemically activated carbons and carbon nanomaterials at high pressures. Carbon 2007; 45: 293-303.

[16] Thomas KM. Hydrogen adsorption and storage on porous materials. Catal Today 2007; 120: 389-98

[17] Zhao W, Fierro V, Zlotea C, Aylon E, Izquierdo MT, Latroche M, Celzard A. Optimization of activated carbons for hydrogen storage. Int J Hydrogen Energy 2011; 36(18): 11746-11751.

[18] Thomas KM. Adsorption and desorption of hydrogen on metal-organic framework materials for storage applications: comparison with other nanoporous materials. Dalton Trans 2009; 9: 1487-505

[19] Tan C, Yang S, Champness NR, Lin X, Blake AJ, Lewis W, Schröder M. High capacity gas storage by a 4,8-connected metal-organic polyhedral framework. Chem Commun 2011; 47: 4487-9. 
[20] Yuan D, Zhao D, Sun D, Zhou H-C. An isoreticular series of metal-organic frameworks with dendritic hexacarboxylate ligands and exceptionally high gas-uptake capacity. Angew Chem Int Ed 2010; 49:5357-61.

[21] Sevilla M, Fuertes AB, Mokaya R. High density hydrogen storage in superactivated carbons from hydrothermally carbonized renewable organic materials. Energy Environ Sci 2011; 4: 1400-10.

[22] Poirier E, Chahine R, Bose TK. Hydrogen adsorption in carbon nanostructures. Int J Hydrogen Energy 2001; 26(8): 831-5. 
Table 1. Textural properties, chemical composition and hydrogen storage properties of polythiophene-derived activated carbons.

\begin{tabular}{|c|c|c|c|c|c|c|c|c|c|}
\hline \multirow[b]{2}{*}{ Sample } & \multicolumn{2}{|c|}{ Textural properties } & \multicolumn{4}{|c|}{ Chemical composition (wt \%) } & \multicolumn{3}{|c|}{ Hydrogen storage } \\
\hline & $\begin{array}{c}\mathrm{S}_{\mathrm{BET}} \\
\left(\mathrm{m}^{2} / \mathrm{g}\right)[\mathrm{a}]\end{array}$ & $\begin{array}{c}\mathrm{V}_{\mathrm{p}} \\
\left(\mathrm{cm}^{3} / \mathrm{g}\right)[\mathrm{a}]\end{array}$ & $\mathrm{S}$ & $\mathrm{C}$ & $\mathrm{O}$ & $\mathrm{H}$ & $\begin{array}{l}\mathrm{H}_{2} \text { uptake } \\
(\mathrm{wt} \%)[\mathrm{b}]\end{array}$ & $\begin{array}{c}\text { Hydrogen uptake } \\
\text { density }\left(\mu \mathrm{mol} \mathrm{H} \mathrm{H}_{2} / \mathrm{m}^{2}\right) \\
{[\mathrm{c}]}\end{array}$ & $\begin{array}{c}\text { Maximum } \mathrm{H}_{2} \\
\text { uptake } \\
(\mathrm{wt} \%)[\mathrm{d}]\end{array}$ \\
\hline PTh & - & - & 28.2 & 57.7 & 11.1 & 2.96 & - & - & - \\
\hline ACT -600 & $1790(1730)$ & $0.89(0.79)$ & 8.5 & 72.3 & 18.0 & 1.24 & $4.55(2.15)$ & 12.7 & 5.27 \\
\hline ACT-700 & $1980(1800)$ & $0.99(0.79)$ & 4.5 & 81.4 & 13.3 & 0.83 & $4.80(2.21)$ & 12.1 & 5.49 \\
\hline ACT-750 & $2810(2560)$ & $1.42(1.15)$ & 2.8 & 87.1 & 9.9 & 0.17 & $5.19(2.34)$ & 9.2 & 5.96 \\
\hline ACT -800 & $3010(2610)$ & $1.57(1.19)$ & 3.4 & 88.3 & 8.2 & 0.13 & $5.40(2.33)$ & 9.0 & 6.27 \\
\hline ACT -850 & $3000(2300)$ & $1.75(1.11)$ & 2.5 & 89.0 & 8.2 & 0.25 & $5.71(2.41)$ & 9.5 & 6.64 \\
\hline
\end{tabular}

[a] Values in parentheses are micropore surface area and micropore volume, which were determined by the t-plot method. [b] Hydrogen uptake measured at 20 bar and $-196{ }^{\circ} \mathrm{C}$. The values in parenthesis correspond to the hydrogen uptake at 1 bar. [c] Values calculated at 20 bar. [d] Value estimated using the Langmuir model. 


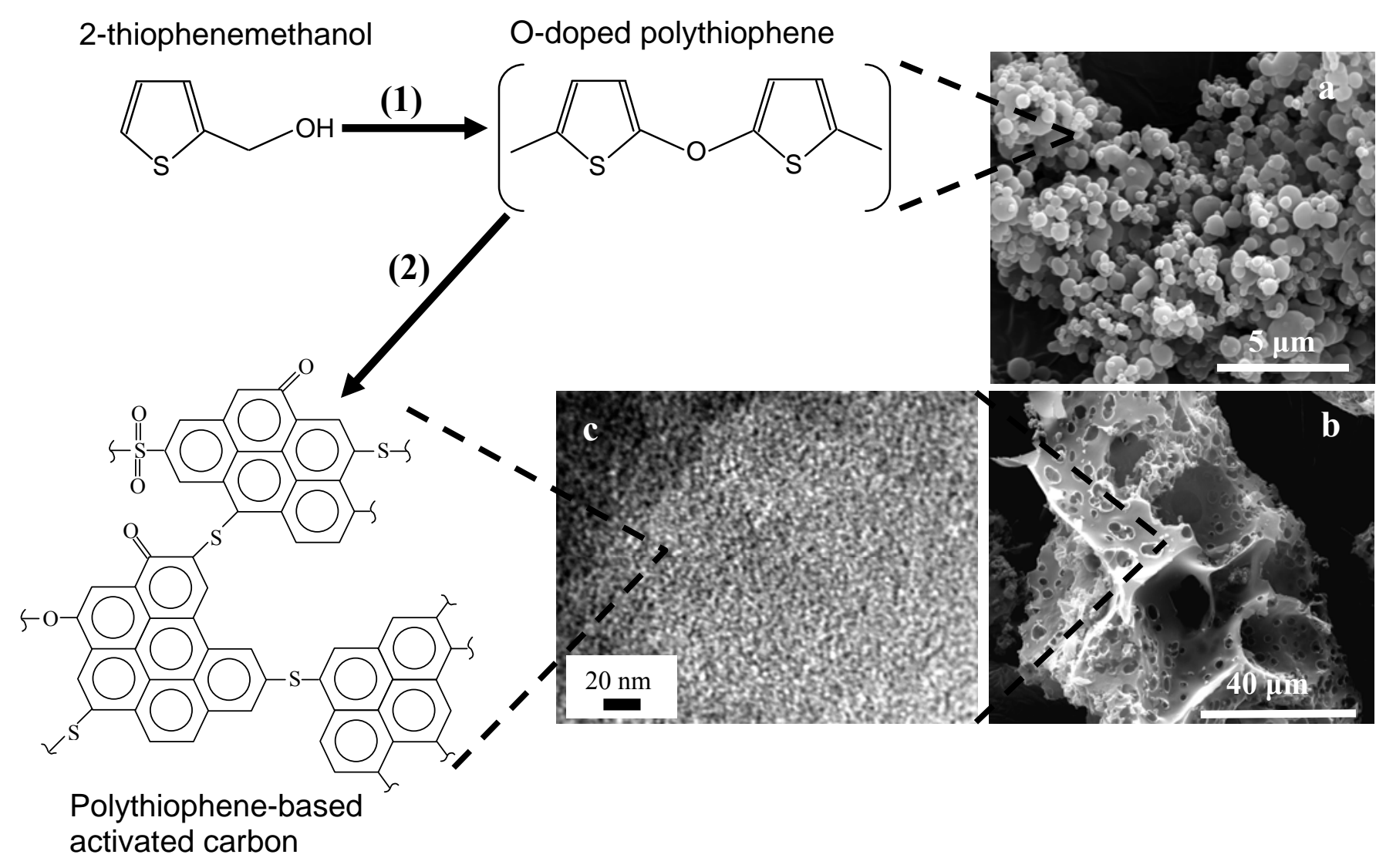

Figure 1. Schematic illustration of the synthesis of polythiophene-based activated carbons. (1) Synthesis of polythiophene and (2) chemical activation of polythiophene. SEM images of (a) polythiophene and (b) activated carbon, and (c) TEM image of the activated carbon. 

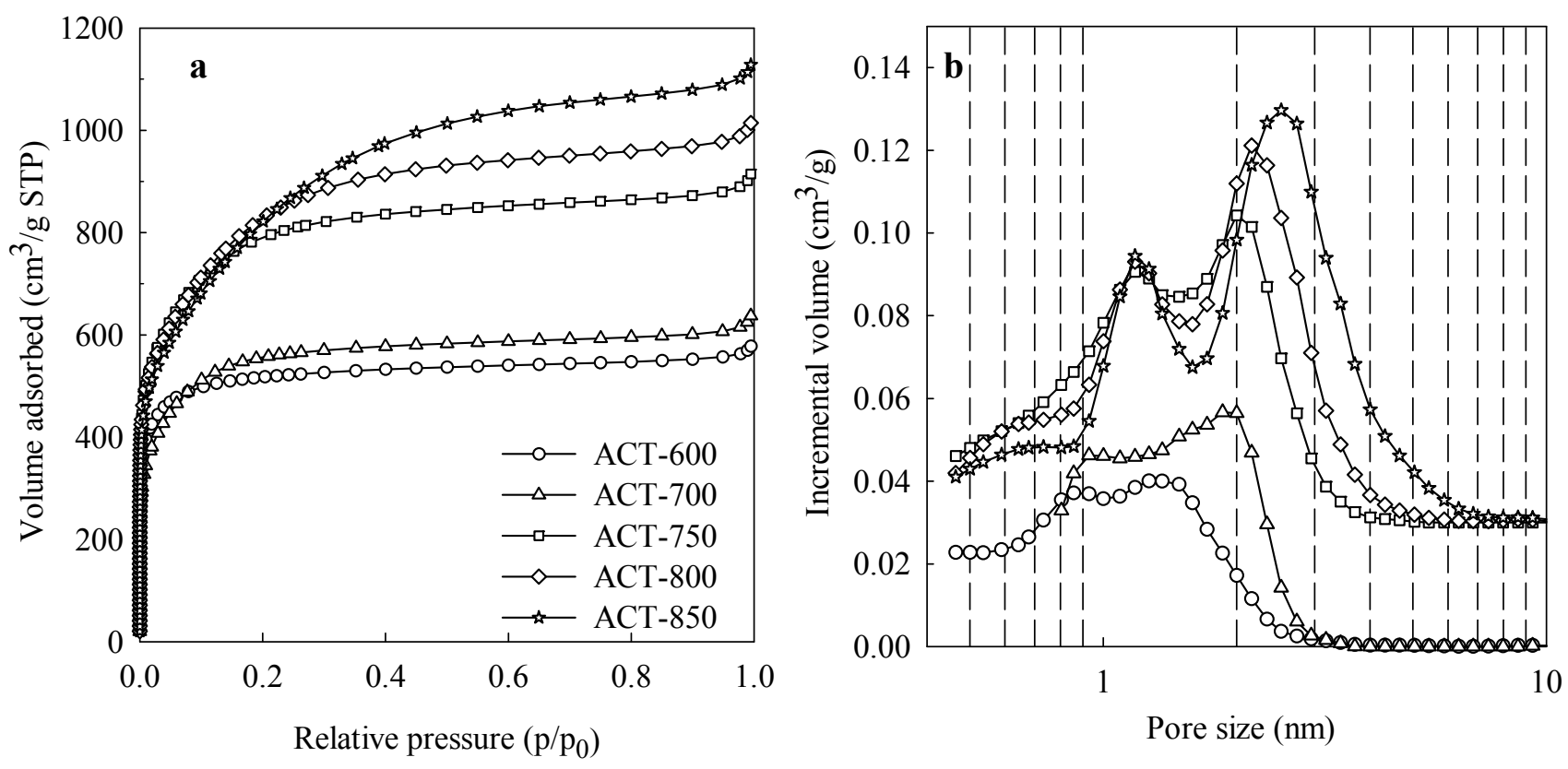

Figure 2. a) Nitrogen sorption isotherms and b) pore size distributions of the porous carbons prepared from polythiophene (PTh) using a weight ratio $\mathrm{KOH} / \mathrm{PTh}=2$ at temperatures in the range $600-850^{\circ} \mathrm{C}$ range. For clarity, the PSD curves of ACT-750, ACT-800 and ACT-850 are off-set (y-axis) by $0.03 \mathrm{~cm}^{3} / \mathrm{g}$. 

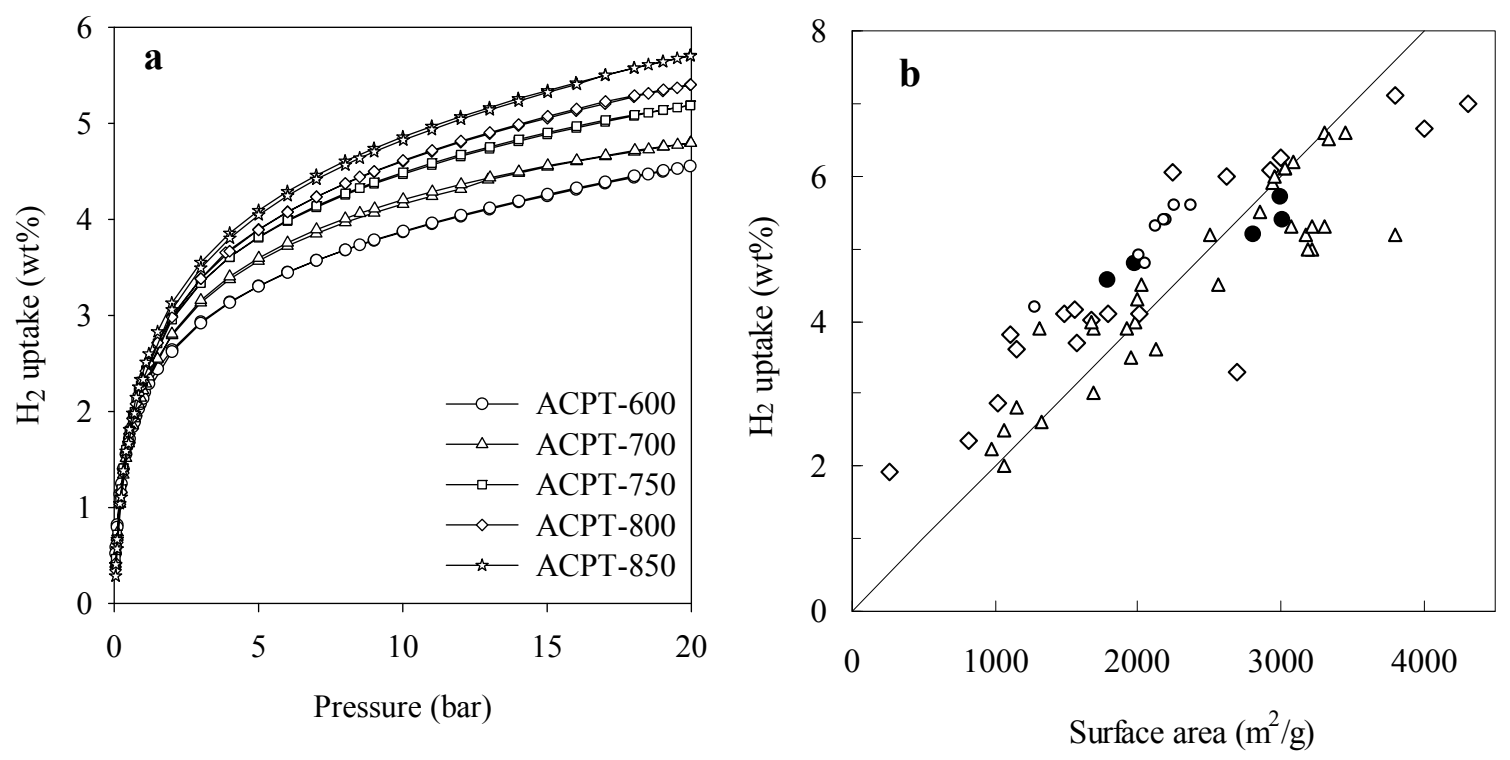

Figure 3. a) Hydrogen sorption isotherms at $-196{ }^{\circ} \mathrm{C}$ of a set of activated carbons prepared at $\mathrm{KOH} /$ polythiophene weight ratio of 2 and activation temperatures in the 600 $-850{ }^{\circ} \mathrm{C}$ range, and b) comparison of the hydrogen uptake capacity (measured at $-196{ }^{\circ} \mathrm{C}$ and 20 bar) vs. surface area for the porous carbons synthesized from polythiophene (O) and other materials found in the literature: one step activated carbons [14-16] $(\triangle)$, MOFS [17-19] $(\diamond)$ and activated carbons from hydrothermally carbonized organic substances [20] $(\bigcirc)$. The solid line corresponds to the Chahine rule [21]. 